\title{
IVIIIIf Eksplorasi Konsep Fisika pada Tari Dhadak Merak Reog Ponorogo
}

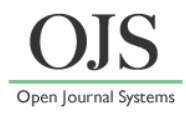

\author{
Nur Iva Wulansari*, Setyo Admoko \\ Jurusan Fisika, Fakultas Matematika dan Ilmu Pengetahuan Alam, Universitas Negeri Surabaya \\ *Email: nur.17030184093@mhs.unesa.ac.id
}

DOI: https://doi.org/10.33369/pendipa.5.2.163-172

\begin{abstract}
Indonesia is famous for its diverse cultures, and unwittingly from each culture has a different appeal. In the culture itself, there is a science that is not widely known by people, besides local wisdom from several regions can be used as a source of learning science. So far, science learning, especially in physics, still refers only to a handbook of teachers and students, where it contains science products in the form of facts, concepts, principles, theories, and laws and their application in the context of daily life. However, many books often contain contexts of daily life related to western culture that is not well recognized by Indonesian children, especially those in certain areas who still rely on nature as a learning media. Based on these problems, the aim to observe the application of physics in Indonesia's national culture. The researcher intended to identify the concept of equilibrium and moments style in the technique of Dhadak Merak dance movement in Reog Ponorogo. This type of research is descriptive qualitative by using documentation studies and the research target is Dhadak Merak Dance. Data collected by the observation method and analysis method using literature study and training video. According to the results of the research, physics concept studies were obtained, especially in equilibrium materials and moments style in the Dhadak Merak Dance, and learning with an ethnoscience approach has the potential for innovation learning to be applied in physics learning because it can train students science literacy and train students to think creatively.
\end{abstract}

Keywords: Ethnoscience, Physics, Dhadak Merak Dance, Equilibrium, Science literacy.

\begin{abstract}
ABSTRAK
Indonesia terkenal akan ragam budayanya, dan tanpa disadari dari setiap budaya memiliki daya tarik yang berbeda. Didalam budaya sendiri, terdapat ilmu sains yang belum banyak diketahui oleh orang, selain itu kearifan lokal dari beberapa daerah yang berbeda dapat dimanfaatkan sebagai sumber belajar dalam bidang sains. Selama ini pembelajaran sains terutama pada bidang fisika yang ada di sekolah sebagian masih mengacu pada buku pegangan guru dan siswa, dimana buku pegangan memuat produk sains berupa fakta, konsep, prinsip, teori, dan hukum serta penerapannya dalam kontek kehidupan sehari-hari. Namun, dalam banyak buku seringkali memuat konteks kehidupan sehari-hari yang terkait dengan budaya barat yang tidak dikenali dengan baik oleh anak Indonesia khususnya mereka yang berada di daerah tertentu yang masih mengandalkan alam sebagai media belajar. Berdasarkan permasalahan tersebut, penelitian ini bertujuan untuk mengamati penerapan konsep fisika yang ada dalam budaya nasional Indonesia. Dimana pada penelitian ini peneliti bermaksud mengidentifikasi kajian konsep kesetimbangan dan momen gaya pada teknik gerakan dhadakan merak dalam tari Reog Ponorogo. Jenis penelitian ini adalah deskriptif kualitatif dengan menggunakan studi dokumentasi dan sasaran penelitian adalah Tari Dhadak Merak. Pengumpulan data dilakukan dengan metode observasi dan metode
\end{abstract}


analisis menggunakan dua metode, yaitu studi literatur dan video latihan. Menurut hasil penelitian, didapatkan kajian konsep fisika terutama pada materi kesetimbangan dan momen gaya dalam Tarian Dhadak Merak, dan pembelajaran dengan pendekatan etnosains memiliki potensi inovasi pembelajaran untuk diterapkan dalam pembelajaran fisika karena dapat melatih literasi sains siswa serta melatih siswa untuk berpikir kreatif.

Kata Kunci: Etnosains, Fisika, Tari Dhadak Merak, Kesetimbangan, Literasi Sains.

\section{PENDAHULUAN}

Fisika adalah ilmu yang mempelajari tentang suatu tingkah laku alam dengan berbagai bentuk gejalanya. Untuk memahami diperlukan pembelajaran fisika dengan penguasaan konsep dasar. Fisika tidak cukup untuk hanya dibaca, dikarenakan fisika tidak sekedar hafalan saja. Maka dari itu, belajar fisika perlu untuk dipahami dan dipraktikkan agar mampu menyelesaikan permasalahan. Pembelajaran fisika termasuk salah satu mata pelajaran yang sangat berpengaruh dalam perkembangan ilmu pengetahuan dan teknologi (Setiawan, 2012).

Secara umum, masalah yang sedang dihadapi oleh pembelajaran fisika hampir sama dengan matematika, di mana sebagian konsep dan prinsip yang digunakan untuk pemecahan suatu masalah. Oleh karena itu, kebanyakan siswa kurang minat terhadap pelajaran fisika yang menjadikan persepsi bahwa pelajaran fisika itu pelajaran yang sulit dan membosankan. Secara tidak langsung persepsi negatif tersebut mempengaruhi hasil belajar yang kurang bagus atau dapat dikatakan cenderung rendah. Selain itu, terdapat beberapa faktor pembelajaran fisika yang lebih fokus pada aspek matematika yang hanya sedikit menekankan pada konsep dan tidak dikaitkan dengan budaya lokal daerah masing-masing (Elvi et al., 2019).

Berdasarkan data PISA 2018, Indonesia mendapat peringkat 72 dari 77 negara untuk kompetensi membaca, untuk nilai matematika berada diperingkat 72 dari 78 negara dan nilai sains berada diperingkat 70 dari 78 negara. Nilai ini cenderung stagnan dalam 10-15 tahun terakhir.

Perlu dipahami bahwa pembelajaran fisika adalah proses untuk memahami pengetahuan secara kontekstual. Hal ini memerlukan pendekatan sains secara ilmiah untuk meningkatkan dan mengembangkan pengetahuan siswa. Peningkatan pengetahuan konsep pada siswa dapat dilihat melalui keterampilan proses sains (Elvi et al., 2019). Pada kenyataannya untuk saat ini, pembelajaran fisika masih belum mampu membuat siswa untuk aktif dan terlibat langsung dalam kegiatan pembelajaran (Istyowati, 2017).

Pembelajaran fisika yang ada di sekolah sebagian besar hanya mengacu pada buku pegangan guru dan siswa, di mana buku pegangan tersebut sudah memuat konsep, fakta, teori dan rumusrumus serta penerapannya pada tiap bab. Namun, dalam buku tersebut cenderung memuat pembelajaran budaya barat yang sering kali tidak dikenali oleh anak Indonesia khususnya pada mereka yang berada di daerah tertentu yang masih mengandalkan alam untuk media belajarnya. Itu menjadi salah satu faktor di mana kebanyakan anak Indonesia sulit untuk memahami fisika dan menjadikan pelajaran fisika kurang bermakna bagi kehidupan sosial budaya mereka (Puspatantri, 2013).

Inovasi pendidikan adalah salah satu perubahan, ide atau gagasan yang merupakan suatu pemikiran cemerlang untuk bisa diterapkan dalam bidang pendidikan untuk memecahkan suatu permasalahan yang ada di lingkungan sekitar masyarakat (Laos \& Tefu, 2019). 
Cara pandang yang sempit akan menghasilkan pengetahuan yang sempit, di mana cara pandang dan penerjemahan budaya masyarakat yang hanya menggunakan satu sisi, dalam hal ini hanya sains asli saja. Maka, tidak dapat meningkatkan pola pikir (Novitasari et al., 2017).

Pembelajaran sains berbasis kearifan lokal atau yang biasa disebut Etnosains merupakan kegiatan pembelajaran yang mentransformasikan antara sains asli dengan kepercayaan masyarakat yang masih mengandung mitos atau kepercayaan turun menurun dan menerapkannya dalam konsep sains ilmiah (Novitasari et al., 2017). Salah satu pembelajaran yang memiliki ranah etnosains dan cabang ilmu yang mempelajari tentang fenomena alam adalah fisika.

Pembelajaran sains di sekolah sekarang masih terpusat pada materi yang ada dalam buku. Jarang sekali pembelajaran sains yang menguak realita budaya di sekitar siswa. Isi materi yang diajarkan masih belum banyak yang mengintegrasikan dengan budaya lokal. Berdasarkan kondisi ini, perlu adanya pengembangan metode pembelajaran, salah satunya dengan menggunakan pendekatan etnosains. Penerapan pembelajaran dengan pendekatan etnosains memerlukan kemampuan guru dalam menggabungkan antara pengetahuan asli dengan pengetahuan ilmiah (Sudarmin et al., 2017).

Secara umum, kearifan lokal muncul dari adanya proses internalisasi yang panjang dan berlangsung turuntemurun sebagai akibat dari interaksi antar manusia dengan lingkungannya. Proses evolusi nilai yang berlangsung cukup panjang ini berujung pada terbentuknya sistem nilai yang terkristalisasi dalam bentuk hukum adat, kepercayaan, dan budaya setempat (Makhmudah, Subikti \& Supeno, 2019).

Salah satu daerah yang budayanya masih kental adalah Jawa. Akan tetapi, upaya penggalian kebudayaan dalam bidang pendidikan masih sangat sedikit sekali dilakukan, hal ini dapat mengakibatkan kurangnya pengetahuan peserta didik sebagai generasi penerus bangsa akan kebudayaan tradisional mereka.

Menurut Sarwanto (2014), sampai sekarang kebudayaan Jawa masih belum banyak digali potensi sains aslinya, baik pada content maupun context pedagoginya. Upaya menggali sains asli Jawa tersebut penting dilakukan, untuk menghindari hilangnya budaya asli Jawa dan menghindari terjadinya bentrokan dan konflik budaya. Salah satu etnosains yang berkembang dimasyarakat adalah tari dhadakan merak yang ada di Reog Ponorogo.

Menurut Hartono (1980) seni pertunjukan reog merupakan tradisi yang masih sangat hidup di lingkungan masyarakat dengan tujuan untuk mempererat tali silaturahmi atar masyarakat di Ponorogo. Selain itu, pertunjukkan reog Ponorogo digunakan sebagai ajang penggerak massa dengan jumlah yang cukup besar.

Barongan (Dhadak Merak) merupakan peralatan tari yang dominan dalam Reog Ponorogo. Bagian dari barongan sendiri terdapat kepala harimau yang terbuat dari kayu, bambu, rotan yang ditutup dengan kulit harimau gembong asli, lalu terdapat singa barong di mana pemain membawa topeng yang berbentuk kepala singa dengan mahkota dari bulu merak dan memperlihatkan keperkasaannya dalam mengangkat Dhadak Merak seberat kurang lebih 50-60 kilogram dengan menggunakan kekuatan gigi untuk mengangkat topeng selama pertunjukkan berlangsung.

Berdasarkan uraian di atas, peneliti menyadari perlunya mengidentifikasi tari Reog Ponorogo khususnya Dhadak Merak sebagai budaya lokal masyarakat Jawa Timur ke dalam pembelajaran fisika. Dan diangkat sebagai topik penelitian yang diintegrasikan dalam konsep kesetimbangan dan gaya yang bertujuan untuk mengembangkan fisika berbasis 
budaya lokal di sekolah dan berkembang dalam masyarakat.

\section{METODE PENELITIAN}

Jenis penelitian yang digunakan adalah penelitian deskriptif kualitatif yaitu dengan menggunakan studi dokumentasi. Tahap penelitian yang dilakukan yaitu: pengumpulan informasi tentang budaya Ponorogo, memilih informasi yang relevan dengan pembelajaran fisika, menganalisis besaran-besaran fisika dalam tari Dhadak Merak, lalu perumusan hasil kajian. Sasaran untuk penelitian ini adalah tari Dhadak Merak pada Reog Ponorogo.

Metode pengumpulan data yang dilakukan dalam penelitian ini menggunakan metode observasi. Metode observasi ini digunakan untuk mendapatkan informasi mengenai tari reog dan menganalisis gerakan gerakan yang terdapat dalam tari Dhadak Merak. Selain itu, metode analisis data yang digunakan terdapat dua metode, yaitu: analisis informasi dari studi literatur, dan analisis observasi berupa video latihan untuk dikaji konsep fisika.

\section{HASIL DAN PEMBAHASAN Ragam budaya Indonesia}

Indonesia adalah negara yang memiliki banyak budaya, seperti budaya orang Jawa yang terkenal dengan kesopanan atau dalam bahasa Jawa adalah unggah-ungguh, budaya sunda yang terkenal akan kelembutannya, dan masih banyak budaya lainnya yang tersebar di wilayah Indonesia.

Lalu, apakah yang dimaksud dengan budaya? Istilah budaya berasal dari bahasa Sansekerta, yaitu buddhayah yang termasuk dalam bentuk jamak dari kata buddhi. Di mana kata buddi sendiri sering diucapkan dalam bahasa Indonesia yaitu budi, yang memiliki arti hal-hal yang berkaitan dengan akal manusia. Sementara itu, istilah budaya jika diambil dari bahasa Inggris culture berasal dari bahasa Latin cultura dari kata dasar colere yang memiliki arti mengolah atau mengerjakan (to cultivate).
Menurut Santrock (2014), budaya mengacu pada perilaku, keyakinan dan suatu hasil lain yang berasal dari sekelompok orang yang diwariskan dari generasi ke generasi. Hasil lain ini merupakan suatu interaksi antara manusia dengan lingkungan sekitar mereka selama bertahun-tahun.

Menurut Koentjaraningrat (1984) kebudayaan terdapat tiga wujud, yaitu kebudayaan yang kompleks dari beberapa ide, kompleks pada suatu aktivitas yang merupakan tingkah manusia dalam masyarakat dan kebudayaan sebagai hasil karya dari manusia yang berbentuk benda.

\section{Kearifan lokal}

Budaya merupakan salah satu wujud dari kearifan lokal yang digunakan sebagai identitas suatu daerah. Secara umum "local wisdom" atau kearifan lokal adalah sesuatu yang biasa dilakukan dan diterapkan oleh masyarakat daerah setempat (Kun, 2013). Dan hampir setiap daerah memiliki ciri khas budaya tersendiri.

Perkembangan suatu kearifan lokal daerah memiliki arti yang penting bagi perkembangan budaya suatu bangsa. Terutama untuk mempertahankan budaya tersebut tetap memiliki arti penting bagi suatu daerah.

\section{Etnosains}

Terdapat salah satu cara yang dapat diterapkan untuk mengolah pengetahuan budaya untuk menghubungkan dengan pengetahuan ilmiah yang mutakhir, di mana cara tersebut adalah dengan menerapkan pengetahuan etnosains. Karena etnosains adalah suatu pengetahuan yang berasal dari budaya serta berperan sebagai dasar pengetahuan realistis dari seseorang yang dapat dihubungkan dengan pengetahuan sains yang didapatkan (Novitasari et al., 2017).

Pengetahuan etnosains merupakan pengetahuan di mana pengetahuan tersebut berasal dari norma dan kepercayaan masyarakat daerah tertentu 
yang akan mempengaruhi interpretasi dan pemahaman terhadap alam (Fasasi, 2017).

Pembelajaran sains dengan pendekatan etnosains merupakan pembelajaran berbasis budaya melalui penggalian pemahaman asli dari siswa terhadap suatu budaya daerah tertentu yang selanjutnya akan ditafsirkan dalam pengetahuan sains (Sudarmin et al., 2017).

Penerapan pembelajaran etnosains memiliki potensi dalam pengembangan metode pembelajaran yang susah ada, di mana sejauh ini terutama pada pembelajaran fisika secara umum masih menggunakan pembelajaran dengan berpusat pada guru. Maka dari itu, apabila pembelajaran etnosains dapat diterapkan di pembelajaran, akan mengubah metode dari pembelajaran berpusat dari guru menjadi pembelajaran berpusat pada siswa. Dengan demikian, siswa diharapkan dapat meningkatkan apresiasi pengetahuan terhadap budaya dan mampu menciptakan situasi pembelajaran yang kontekstual dan penuh dengan makna, agar pengetahuan yang di dapat siswa menjadi pengetahuan atau pemahaman jangka panjang (Atmojo, 2012).

Selain pembelajaran etnosains menjadikan pengetahuan siswa untuk mengingat menjadi pemahaman jangka panjang dan lebih memiliki makna, ternyata pembelajaran dengan etnosains dapat mendorong minat siswa untuk belajar mengenal ilmu pengetahuan alam dengan memanfaatkan lingkungan sekitarnya (Novia et al., 2015).

Pembelajaran berbasis budaya ini ternyata mampu membuat siswa tidak hanya menerima informasi yang disampaikan saja. Melainkan, siswa juga mampu menciptakan makna, pemahaman dan mengembangkan pengetahuan yang sudah diperolehnya. Selain itu, dalam proses pembelajaran ini tidak hanya mampu mentransfer budaya dalam perwujudannya, tetapi dengan budaya dapat menjadikan siswa mampu membuat makna, menembus batas imajinasinya dalam mencapai pemahaman yang mendalam dan ternyata siswa mampu menjadi lebih kreatif dalam mata pelajaran yang dipelajari.

Pembelajaran fisika berbasis etnosains dapat melatih kemampuan literasi sains siswa, dan membuat siswa dapat berpikir kritis dengan melatih kepekaan terhadap lingkungan sekitar. Selain itu, siswa juga dapat lebih mengeksplor lingkungan sekitarnya dan pembelajaran yang dilakukan tidak cenderung membosankan bagi siswa.

\section{Kajian etnosains tari Dhadak Merak}

Hasil kajian dari tari Dhadak Merak

Reog Ponorogo menunjukkan adanya nilai kearifan lokal dan potensi etnosains yang dapat diterapkan sebagai referensi pembelajaran sains.

Budaya seni tradisional yaitu kesenian Reog yang populer di Jawa Timur. Sekitar 17 daerah di Jawa Timur terdapat seni pertunjukkan Reog seperti kota Surabaya, Mojokerto, Jombang, Kediri, Magetan, Nganjuk, Ngawi, Pacitan, Trenggalek, Sidoarjo, Tulungagung dan Kabupaten Ponorogo yang merupakan tempat berkembangnya seni pertunjukan Reog (Trisakti, 2012).

Meskipun seni Reog terdapat di berbagai daerah di Jawa Timur, namun seni Reog ini sudah menjadi ikon khas Kabupaten Ponorogo. Reog Ponorogo termasuk dalam seni pertunjukan tradisional yang memiliki latar belakang pementasan yang sangat beragam. Kesenian ini telah menjadi bagian hidup dari masyarakat yang menyimbolkan sekaligus menjadi representasi dari aktivitas keseharian masyarakat.

\section{Hasil analisis konsep fisika pada tari Dhadak Merak}

Hasil analisis peneliti dari kajian berbagai literatur menunjukkan bahwa dalam gerakan tari dhadakan merak pada saat pertunjukkan seorang pemain memanggul kepala singa dengan hiasan bulu merak atau disebut dengan Dhadak Merak yang memiliki berat sekitar 50-60 $\mathrm{kg}$ dan hanya menggunakan gigi. Hal tersebut dapat dilakukan karna latihan 
fisik yang cukup lama dan dilakukan oleh pemain yang profesional.

Konsep fisika yang ada saat Dhadak Merak pada posisi berdiri adalah Hukum Newton I, yaitu:

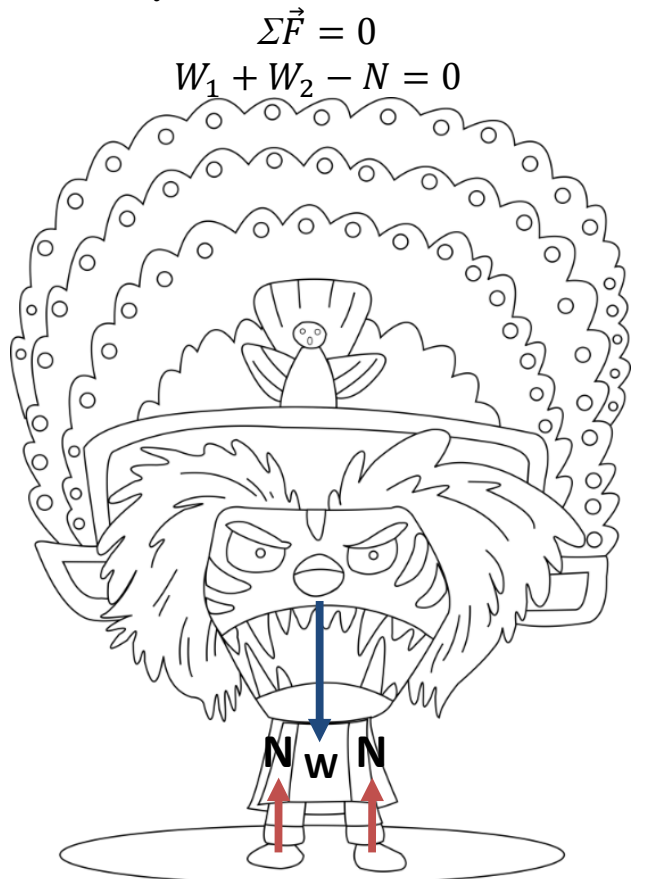

Gambar 1. Posisi pemain Dhadak Merak berdiri

Saat posisi berdiri, posisi kaki membuka dengan keadaan merendah. Lalu untuk kedua lengan membentuk siku-siku dengan posisi telapak tangan menghadap ke depan. Ketika lengan tangan membentuk siku-siku, terdapat kontraksi dari otot bisep yang menjadi lengan kuasa yang dihasilkan dari hasil oksidasi dalam tubuh melalui bahan makanan yang dikonsumsi oleh pemain Dhadak Merak (Erman, 2016).

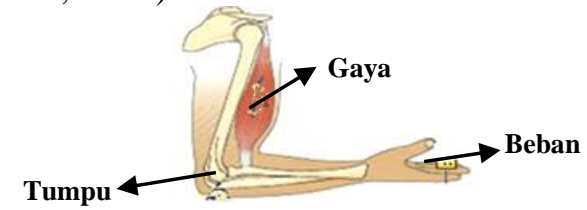

\section{Gambar 2. Skema lengan pemain Dhadak Merak}

Posisi kepala tegak dengan leher menyangga beban yaitu Dhadak Merak yang digigit. Pada situasi ini tekanan pada leher sangat kuat, maka benar-benar dapat menahan Dhadak Merak dalam kondisi stabil atau seimbang (Wahyuni et al., 2019).

Selain itu, terdapat konsep usaha di mana suatu aktivitas yang dilakukan manusia menggunakan sejumlah energi. Konsep ini ada di saat penari Dhadak Merak mencoba bergerak ke kanan atau ke kiri.

$$
W=\vec{F} . S
$$

Selain gaya, power atau daya untuk mendeskripsikan ukuran suatu usaha juga termasuk. Dengan perbandingan antara usaha (W) dengan waktu (t) akan didapatkan koefisien kerja dari suatu gerakan yang dilakukan oleh penari Dhadak Merak, yaitu:

$$
P=\frac{W}{t}
$$

Dari usaha dan daya tersebut, upaya yang dilakukan penari melakukan tindakan yang efisien dan dapat dihitung melalui keuntungan mekanis yang di dapat dengan perbandingan antara gaya yang dihasilkan dengan gaya yang diberikan oleh pemain.

$$
K=\frac{\overrightarrow{F_{O}}}{\overrightarrow{F_{l}}}
$$

Dapat dilihat bahwa di sini terdapat konsep pesawat sederhana, dengan tujuan utama untuk mendapatkan nilai dari keuntungan mekanis agar posisi Dhadak Merak dapat tetap seimbang.

Karena untuk menopang Dhadak Merak menganut konsep mengangkat beban berat, dibutuhkan posisi yang tepat dengan usaha yang dibutuhkan juga cukup besar. Hal ini juga dipengaruhi oleh gaya otot yang mengakibatkan energi yang berkurang karena diperlukan usaha yang besar dengan mempertimbangkan agar saat berdirinya Dhadak Merak tetap seimbang. Energi ini diperoleh dari makanan melalui proses metabolisme tubuh.

Pada saat menganggukkan kepala ke depan dengan tetap menggigit Dhadak Merak, kepala dan leher bekerja sebagai tuas dengan titik tumpuk puncak leher. Otot leher berperan memberikan gaya 
kuasa untuk menarik kepala ke posisi semula.

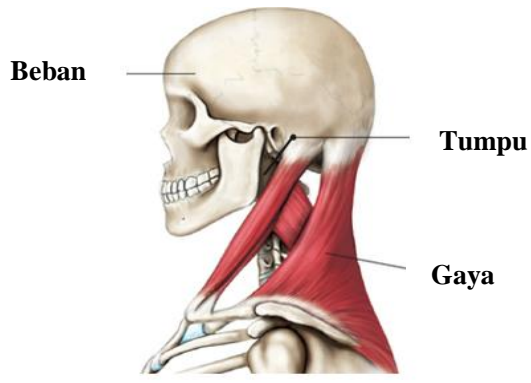

Gambar 3. Skema saat pemain Dhadak Merak menggerakkan topeng Dhadak Merak ke depan atau ke belakang

Terkadang pemain Dhadak Merak juga melakukan gerakan atraksi dengan kaki yang berjinjit, bagian ujung kaki inilah yang menjadi titik tumpu. Selain itu, ternyata dengan berjinjit dapat melatih keseimbangan badan.

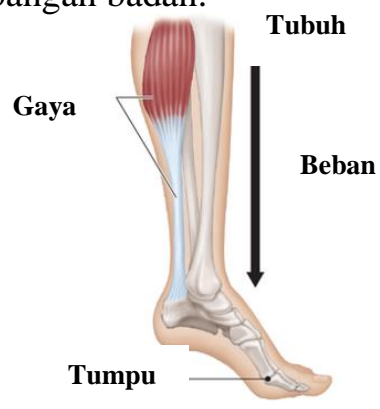

Gambar 4. Skema kaki pemain Dhadak Merak saat berjinjit

Agar saat melakukan atraksi pemain Dhadak Merak tetap seimbang maka posisi kaki harus diatur sedemikian pula,

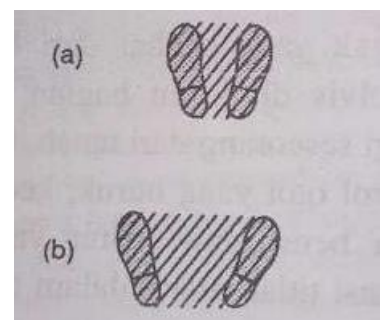

\section{Gambar 5. Posisi kaki saat berdiri untuk menghasilkan daerah stabil}

Posisi kaki sebagai penopang, dan keadaan tubuh pada penempatan titik berat yang sempurna harus menjadi fokus pemain tari Dhadak Merak. Lalu pada saat sudah memanggul dan bergeraknya
Dhadak Merak adalah adanya konsep Hukum Newton II, yaitu:

$$
\Sigma \vec{F}=m \cdot \vec{a}
$$

Di mana dari Hukum Newton II ini dapat diturunkan menjadi:

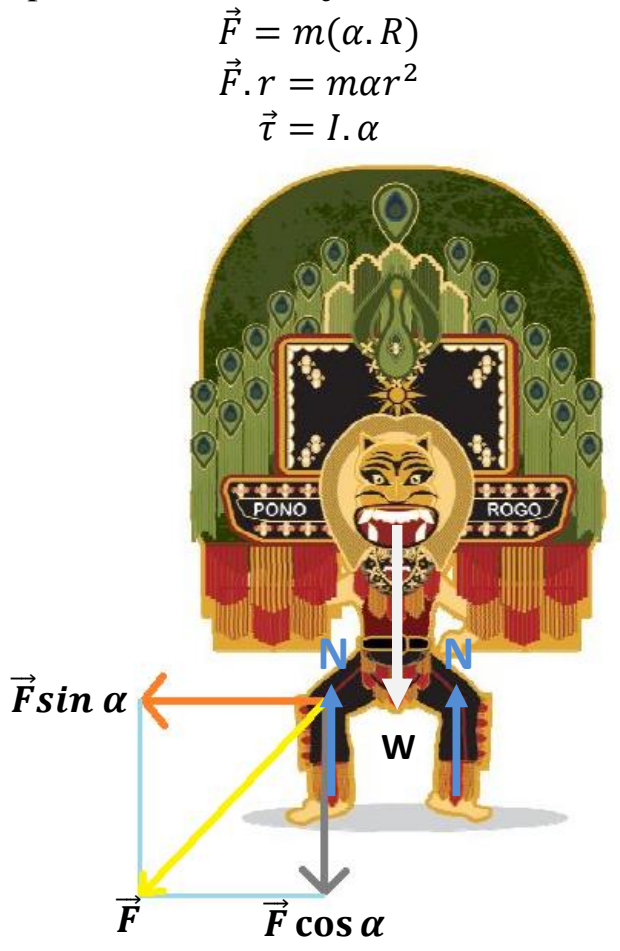

Gambar 6. Posisi bergerak Dhadak

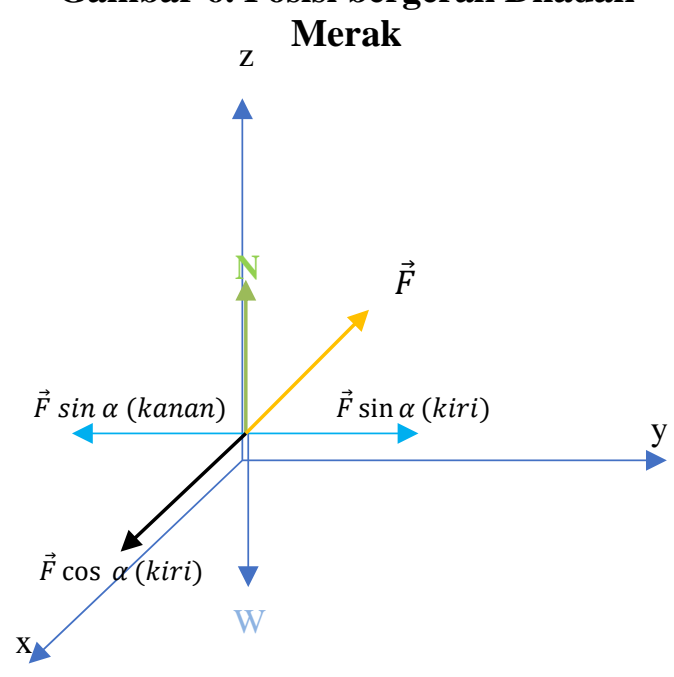

\section{Diagram gerak Dhadak Merak}

Karena pergerakan Dhadak Merak juga berputar tidak hanya berdiam diri dengan menahan beban berat, maka menganut konsep torsi, yaitu: 


$$
\vec{\tau}=\vec{F} \cdot r \sin \varphi
$$

Di $\operatorname{mana} r \sin \varphi$ atau biasanya $d$ adalah lengan momen. Nilai gaya-gaya dan torsi yang bekerja berdasarkan diagram gerak adalah:

$$
\begin{aligned}
\Sigma \vec{F}=0, & & \Sigma \vec{\tau}=0 \\
\Sigma \vec{F}_{x}=0, & & \Sigma \vec{\tau}_{x}=0 \\
\Sigma \vec{F}_{y}=0, & & \Sigma \vec{\tau}_{y}=0 \\
\Sigma \vec{F}_{z}=0, & & \Sigma \vec{\tau}_{z}=0
\end{aligned}
$$

Pemain memfokuskan pusat massa tubuh di bagian tengah dengan kedua kaki sebagai penopang berat badan. Dada dicondongkan ke depan, tulang belikat ditarik ke belakang untuk membuat kesan tegap dan optimis. Sikap ini dapat disebut gaya perlawanan dari gaya.

Saat sedang bergerak, pemain Dhadak Merak juga harus kuat posisi kuda-kudanya, hal ini merupakan salah satu trik untuk mengumpulkan tenaga pada paha sehingga kaki menjadi lebih kuat. Dikatakan seimbang apabila dhadakan merak dalam keadaan stabil, yaitu:

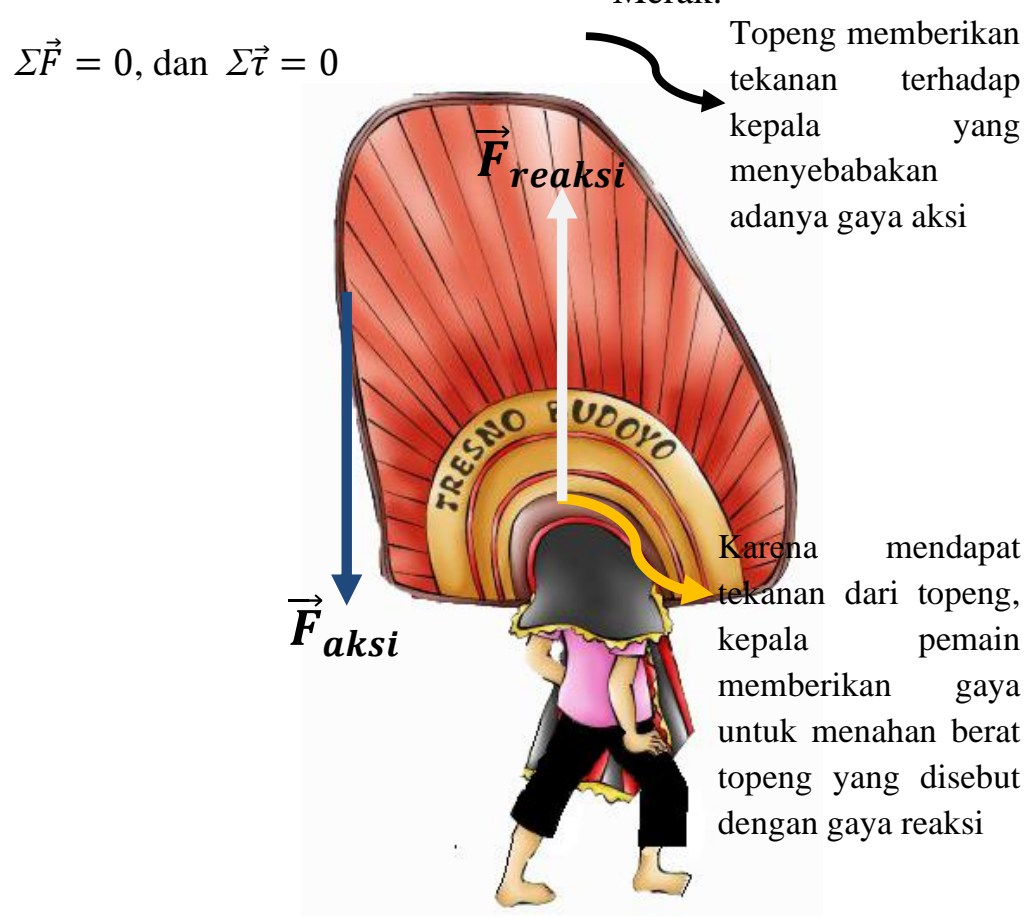

\section{Gambar 6. Ilustrasi Hukum Newton III pada Topeng Dhadak Merak Terhadap Kepala Pemain}

Selain dengan latihan fisik dan kuda-kuda yang kuat, dipercayai bahwa
Selain itu juga menganut konsep Hukum Newton III, yaitu:

$$
\vec{F}_{a k s i}=-\vec{F}_{\text {reaksi }}
$$

Konsep ini berlaku saat posisi pemain tari Dhadak Merak sedang berdiri dan mempertahankan posisi topeng agar tetap seimbang. Gaya-gaya yang menganut konsep Hukum Newton III ada pada topeng Dhadak Merak yang menekan kepala pemain tari Dhadak Merak. Gaya aksi $\left(\vec{F}_{a k s i}\right)$ diberikan oleh topeng yang menekan kepala dan mengarah ke bawah atau ke pusat bumi, sedangkan untuk Gaya reaksi $\left(-\vec{F}_{\text {reaksi }}\right)$ terdapat pada kepala manusia atau kepala dari pemain tari Dhadak Merak.

Di mana dijelaskan bahwa Hukum Newton III dapat bekerja apabila memiliki besar gaya yang sama dengan arah berlawanan dan bekerja pada benda yang berbeda, maka dari itu untuk konsep Hukum Newton III bekerja pada topeng terhadap kepala pemain tari Dhadak Merak.

Topeng memberikan tekanan terhadap menyebabakan adanya gaya aksi memberikan gaya untuk menahan berat topeng yang disebut dengan gaya reaksi

terdapat satu faktor lain yang membuat pemain dapat melakukan gerakan berputar 
atau atraksi hanya menggunakan kekuatan gigi untuk menahan Dhadak Merak, yaitu adanya kekuatan dari latihan spiritual dengan berpuasa dan bertapa.

\section{KESIMPULAN}

Berdasarkan hasil dan pembahasan di atas, dapat disimpulkan bahwa di setiap pergerakan yang dilakukan oleh penari Dhadak Merak dapat dikaji dengan ilmu fisika. Dalam teknik tari Dhadak Merak terdapat kajian konsep fisika yang meliputi: gaya berat di mana dikendalikan oleh otot dan kesetimbangan dari kudakuda pemain Dhadak Merak yang dikaji dari Hukum Newton I, II dan III untuk mempertahankan titik beratnya tetap pada posisi.

Apabila gerakan yang dilakukan pemain semakin cepat, maka energi pemain akan banyak terkuras karena usaha yang dilakukan cukup besar. Di mana konsep tersebut dapat berkembang dimasyarakat tanpa disadari bahwa hal ini disebut dengan sains asli masyarakat. Melalui pembelajaran fisika dengan etnosains dapat membantu masyarakat untuk memperbaiki pengetahuan sains asli dari masyarakat menjadi ilmu sains yang sesungguhnya.

Untuk penelitian selanjutnya dapat dilakukan dengan mengkaji konsep yang lain, dan disarankan mencari referensi yang lebih banyak untuk membantu menganalisis kajian konsep yang ada pada Tari Dhadak Merak.

\section{UCAPAN TERIMA KASIH}

Dalam penyusunan artikel ini penulis mengucapkan terima kasih atas motivasi, masukan, kritik, dan saran yang bersifat membangun kepada:

1) Dr. Munasir, S.Si., M.Si. selaku Ketua Jurusan Fisika.

2) Nadi Suprapto, Ph.D. selaku Ketua Prodi Pendidikan Fisika

3) Nadi Suprapto, Ph.D. dan Utama Alan Deta, S.Pd., M.Pd., M.Si. selaku dosen penguji
4) Kedua Orang tua serta saudara atas semua doa dan bantuan baik material maupun moral

5) Teman-teman "Saudara Fisika" angkatan 2017.

\section{DAFTAR PUSTAKA}

Abonyi, S. O,. Achimugu, L., \& Njoku, M. I. (2014). Innovations in Science and Technology Education: A Case for Ethnoscience Based Science Classroom. International Journal of Scientific \& Engineering Research, $5(1)$.

Atmojo, S. E. (2012). Profil keterampilan proses sains dan apresiasi siswa terhadap profesi pengrajin tempe dalam pembelajaran ipa berpendekatan etnosains. Jurnal Pendidikan IPA Indonesia, 115122.

Elvi, V., Husin, R., \& Billik, H. (2019). Identifikasi Konsep Fisika Pada Kearifan Lokal Anyaman Di Kabupaten Timor Tengah Selatan. Jurnal Fisika Fisika Sains dan Aplikasinya. 4(2), 153-158.

Erman, Rudiana, dan Muslimin Ibrahim. (2016). Pengembangan Buku Ajar Pembelajaran IPA Berbasis Kearifan Lokal sebagai Pedoman Guru Meningkatkan Literasi Sains Siswa SMP. Surabaya: Universitas Negeri Surabaya.

Fasasi, R. A. (2017). Effects of ethnoscience instruction, school location, and parental educational status on learners' attitude towards science. International Journal of Science Education, 1-17.

Istyowati, et al. (2017). Analisis Pembelajaran dan Kesulitan Siswa SMA Kelas XI Terhadap Penguasaan Konsep Fisika. April, 237-243.

Kun, P. Z. (2013). Pembelajaran Sains Berbasis Kearifan Lokal. PROSIDING: Seminar Nasional Fisika Dan Pendidikan Fisika. 4, hal. 2332. Surakarta 
Laos, L. E., \& Tefu, M. (2019). Identifikasi Konsep Fisika Pada Kearifan Lokal Pengolahan Sagu (Putak) Kabupaten Timor Tengah Selatan. Jurnal Fisika: Fisika Sains Dan Aplikasinya.

Makhmudah, N. L., Subiki, \& Supeno. (2019). Pengembangan Modul Fisika Berbasisi Kearifan Lokal Permainan Tradisional Kalimantan Tengah Pada Materi Momentum dan Impuls. Jurnal Pembelajaran Fisika, 8, 181-186

Novia, Nurjannah, \& Kamaluddin. (2015). Penalaran Kausal dan Analogi Berbasis Etnosains dalam Memecahkan Masalah Fisika. Jurnal Pendidikan Fisika Dan Teknologi.

Novitasari, L., Agustina, P. A., Sukesti, R., Nazri, M. F., \& Handhika, J. (2017). Fisika, Etnosains, dan Kearifan Lokal dalam Pembelajaran Sains. Seminar Nasional Pendidikan Fisika III 2017, 81-88.

OECD. (2020). Science performance (PISA) (indicator). doi: 10.1787/91952204-en (Accessed on 10 November 2020).

Puspatantri, C. D. A. (2013). Eksplorasi Tari Pendet Sebagai Media Belajar Dalam Pembelajaran Fisika Berbasis Budaya Skripsi. Journal of Chemical Information and Modeling, 53(9), 1689-1699.

Rizqiyah, A. N. (2018). Garap Gerak Pembarong Putri dalam Pertunjukan Reog di Paguyuban Sardulo Nareshwari Ponorogo.
Santrock, John W. (2014). Psikologi Pendidikan: Educational Psychology Edisi 5 Buku 1. Jakarta: Penerbit Salemba Humanika.

Setiawan, A., \& Hamidah, I. (2012). "Pembelajaran Berbasis Virtual Laboratory untuk Meningkatkan Penguasaan Konsep pada Materi Listrik Dinamis". Proceeding of The $4^{\text {th }}$ International Conference on Teacher Education; Join Conference UPI \& UPSI Bandung, Indonesia, 688-692.

Sudarmin, Febu, R., Nuswowati, M., \& Sumarni, W. (2017). Development of Ethnoscience Approach in the Module Theme Substance Additives to Improve the Cognitive Learning Outcome and Student's entrepreneurship. Journal of Physics: Conference Series. https://doi.org/10.1088/17426596/824/1/012024.

Trisakti. (2012). Pemetaan Seni Pertunjukan Tradisional Jawa Timur sebagai Strategi Pelestarian Seni Budaya Tradisional. Laporan Penelitian Strategis Nasional, Universitas Negeri Surabaya, Lembaga Penelitian dan Pengabdian Kepada Masyarakat.

Wahyuni, S., Handhika, J., \& Kurniadi, E. (2019). Makalah Pendamping ISSN : 2527-6670 Apersepsi Pencak Silat pada Materi Gelombang Bunyi untuk Pembelajaran Fisika. 